\title{
Correction to: Parseval Proximal Neural Networks
}

\author{
Marzieh Hasannasab ${ }^{1}$. Johannes Hertrich ${ }^{1} \cdot$ Sebastian Neumayer $^{1}$. \\ Gerlind Plonka ${ }^{2} \cdot$ Simon Setzer ${ }^{3}$. Gabriele Steidl ${ }^{1}$
}

Published online: 28 April 2021

(c) Author(s) 2021

\section{Correction to: Journal of Fourier Analysis and Applications https://doi.org/10.1007/s00041-020-09761-7}

This article was originally published Online First without Open Access. After publication in volume 26, issue 4, the author decided to opt for Open Choice and to make the article an Open Access publication. Therefore, the copyright of the article has been changed to $\odot$ The Author(s) 2021 and the article is forthwith distributed under the terms of the Creative Commons Attribution 4.0 International License, which permits use, sharing, adaptation, distribution, and reproduction in any medium or format, as long as you give appropriate credit to the original author(s) and the source, provide a link to the Creative Commons license, and indicate if changes were made. The images or other third party material in this article are included in the article's Creative Commons license, unless indicated otherwise in a credit line to the material. If material is not included in the article's Creative Commons license

The original article can be found online at https://doi.org/10.1007/s00041-020-09761-7.

Sebastian Neumayer

neumayer@math.tu-berlin.de

Marzieh Hasannasab

hassanasab@math.tu-berlin.de

Johannes Hertrich

j.hertrich@math.tu-berlin.de

Gerlind Plonka

plonka@math.uni-goettingen.de

Simon Setzer

simon.setzer@gmail.com

Gabriele Steidl

steidl@math.tu-berlin.de

1 Institute of Mathematics, TU Berlin, Straße des 17. Juni 136, 10623 Berlin, Germany

2 Institute for Numerical and Applied Mathematics, Göttingen University, Lotzestr. 16-18, 37083 Göttingen, Germany

3 London, UK 
and your intended use is not permitted by statutory regulation or exceeds the permitted use, you will need to obtain permission directly from the copyright holder. To view a copy of this license, visit http://creativecommons.org/licenses/by/4.0.

Publisher's Note Springer Nature remains neutral with regard to jurisdictional claims in published maps and institutional affiliations. 